\title{
Raça, classe e a "universalidade insurgente"
}

\section{Race, class and the insurgent universality}

\section{Emily Almeida Azarias}

Jornalista e mestranda no Programa de Pós-Graduação em Comunicação e Cultura da Universidade Federal do Rio de Janeiro.

\section{Pamela Mariana Queiroz Santana}

Mestranda no Programa de Pós-Graduação em Comunicação e Cultura da Universidade Federal do Rio Janeiro.

\section{RESUMO}

O presente trabalho traça um panorama da obra Armadilhas da identidade, de Asad Haider, evidenciando os principais pontos e tensionamentos entre raça, classe e políticas de identidade. Asad baseia a escrita em sua experiência enquanto filho de imigrantes paquistaneses nos Estados Unidos e discute, por um viés marxista, a interferência do neoliberalismo nas ações políticas que envolvem os debates raciais, diferenciando "identitarismo" de "políticas de identidade". Esta resenha, por sua vez, busca delinear pontes entre o contexto estadunidense e o brasileiro a partir da obra de intelectuais que, qualificadamente, discutem raça e classe na América Latina.

PALAVRAS-CHAVE: Políticas de identidades; Identitarismo; Classe; Racismo; Branquitude.

\section{ABSTRACT}

The current work analyses Armadilhas da Identidade, a book from Asad Haider, highlighting its main concerns about race, class and identitarianism. Asad's writing is grounded in his own experience as a son paquistanese immigrants. For Haider, who discusses the theme from a Marxist perspective, the interference of neoliberalism in racial debates differentiates what is known as "identitarianism" and as "identity policies". This review seeks to set paths between the US and Brazilian contexts, based on the work of intellectuals who are qualified to discuss race and class in Latin America.

KEYWORDS: identity politics; identity; class; racism; whiteness

Dossiê Guerras Culturais - https://revistaecopos.eco.ufrj.br/

ISSN 2175-8689-v. 24, n. 2, 2021

DOI: 10.29146/ecopos.v24i2.27771 
Confrontar se o que está no centro do debate é raça ou classe ou qualquer categoria de identidade é sempre um terreno arriscado para os autores que se propõem a fazê-lo, sob o risco de acabar minimizando as conquistas daqueles à margem do patriarcado supremacista branco capitalista, como bell hooks descreve; ou de limitar-se às particularidades, inviabilizando transformações coletivas e a crítica sobre os valores burgueses. Mesmo assim, em "Armadilhas da identidade Raça e Classe nos dias de hoje", o historiador Asad Haider se empenha em encarar esse dilema no campo da filosofia política com o fim de superá-lo e, assim, dar base a mudanças na estrutura de poder neoliberal. Também ativista, ele parte do marxismo para discutir identidade, justiça racial e poder econômico.

Estadunidense e filho de paquistaneses em pleno pós-11 de setembro, o autor - que não é negro ou afroamericano, nem branco ou europeu- articula reflexões e práticas de intelectuais revolucionários negros dos Estados Unidos numa pesquisa sobre história da racialidade, do racismo e dos movimentos antirracistas, para tensionar os limites das categorias de classe e de raça. Os dados biográficos do autor são salientados pelo próprio ao longo da obra para conduzir uma narrativa a partir da própria experiência de reflexão. “Todos nós nascemos em algum lugar, escreveu o filósofo Louis Althusser", como abre o livro. Assim, ele reconhece como esses aspectos atravessam suas escolhas e subjetividades, ao mesmo tempo em que recusa as fronteiras impostas a pessoas não brancas.

O leitor é levado a pensar identidade não sob o ponto de vista cultural ou moral, mas sobretudo sob a ótica da prática política: como uma categoria nebulosa da contemporaneidade que reinscreve um ideal burguês masculinista e que renaturaliza o capitalismo. "Reivindicar inclusão na estrutura da sociedade como ela 
é significa se privar da possibilidade de mudança estrutural" (p.65), questiona. Haider avalia que as lutas políticas auto-organizadas dos oprimidos contra a supremacia branca conseguiram enfraquecê-la significativamente, mas sem eliminá-la. Simultaneamente, a falta de uma organização coletiva de massa no campo do socialismo que reconheça as singularidades dos trabalhadores é preenchida pela ideologia racial, fortalecendo o racismo em vez da luta de classes. “E sem a divisão política de trabalho que Haywood ${ }^{1}$ descreve, a luta contra o racismo fica reduzida à reparação de lesões individuais."(p.158), resume Haider.

Lançado em 2018 nos Estados Unidos com o título original "Mistaken identity: race and class in the age of Trump", a obra descreve a ascensão dos movimentos pelos direitos civis em confronto com onda reacionária que precedeu a eleição da extrema-direita levando Donald Trump à presidência dos EUA. No mesmo ano, o jurista e intelectual negro Silvio Almeida lançava no Brasil o livro "Racismo Estrutural", parte da coleção "Feminismos plurais", coordenada pela filósofa Djamila Ribeiro e que traz produções de autores negros, sobretudo mulheres, para explicar de forma introdutória temas e conceitos relativos a gênero e raça, mas que acabaram, de certo modo, tendo seus debates esvaziados no âmbito das discussões midiáticas, em meios digitais e eletrônicos. É Almeida que faz o prefácio da obra de Haider para o lançamento no Brasil, em 2019, traduzida por Leo Vinícius Liberato. Mesmo período também da ascensão da extrema direita no país. Almeida destaca que o livro provoca a pensar identidade para além das amarras ideológicas que as recriam dentro das determinações materiais da vida social.

\footnotetext{
${ }^{1}$ Conforme descrito no livro, Harry Haywood, ao lado Cyril Briggs e Claude McKay, fazia parte da organização clandestina comunista African Blood Brotherhood, incorporada pelo Partido Comunista na década de 1920. Mais tarde, no manifesto Black Bolshevik (Chicago, Liberator Press, 1978), Haywood criticou o que chamou de "guerra de araque contra o chauvinismo branco", que não mobilizava massas, mas se limitava a policiar a linguagem dos ditos camaradas.
} 
1.

No primeiro capítulo, Haider tece uma crítica ao que chama de "política identitária", expressão que surgiu em Boston na década de 1970 no discurso do coletivo de mulheres negras lésbicas Combahee River, o CCR, ao criticar as práticas e discursos racistas e sexistas no movimento de esquerda. Para o autor, em referência ao também historiador Salar Mohandesi, ainda que o CCR estivesse apontando as limitações do socialismo para superá-las, a crítica acabou sendo aproveitada na forma prática contemporânea pelas propostas neoliberais reformistas, esvaziando as bases de movimentos de massa. Assim, ele descreve a política identitária como uma perspectiva baseada no reconhecimento individual e defende, em contraponto, uma solidariedade contra o retrocesso.

O paradigma da identidade reduz a política a quem você é como indivíduo e a ganhar reconhecimento como indivíduo, em vez de ser baseada no seu pertencimento a uma coletividade e na luta coletiva contra uma estrutura social opressora. Como resultado, a política identitária paradoxalmente acaba reforçando as próprias normas que se propõe a criticar. (Haider, 2019, p.61).

Haider lembra que identidade é uma abstração que nada diz sobre as relações que as constituíram e rejeita formas de individualidade como ponto de partida. Para ele, o problema das "identidades politizadas" é que as demandas políticas feitas por essas não são colocadas "a partir do contexto de uma insurgência vinda de baixo" (p.69), das margens, acabando por recorrer ao ideal de classe média branca e masculina, uma "burguesia multicultural".

2.

"Contradições entre as pessoas" é o capítulo onde Haider exemplifica as manifestações contra o aumento das mensalidades na universidade norteamericana

Dossiê Guerras Culturais - https://revistaecopos.eco.ufrj.br/

ISSN 2175-8689-v. 24, n. 2, 2021

DOI: 10.29146/ecopos.v24i2.27771 
em que era estudante, onde o que nasceu como um movimento antirracista revolucionário passou a ser utilizado enquanto política identitária, a decisão das *pessoas de cor* de se distanciar das movimentações gerais contra o aumento das mensalidades. 0 grupo tomou a decisão de tocar o movimento a partir de um viés de identidade, mesmo que o aumento das mensalidades também atingisse pessoas brancas pobres e outros jovens não brancos. Este posicionamento causou incômodo ao autor.

O fato coincidiu com a campanha presidencial de Hillary Clinton nos EUA (2016) contra Bernie Sanders, pautada por expressões como "interseccionalidade" e "privilégio", quando, na prática, seu liberalismo agia diretamente comunidades negras.

A partir disso, ele aponta como o uso equivocado do conceito de "interseccionalidade", encabeçado por Kimberlé Crenshaw, é entendido na prática política como um acúmulo de opressões, distanciando os indivíduos de uma solidariedade fundamental para o processo de organização política. Para Haider, a apropriação desse discurso afasta outras identidades em processo de subordinação para longe das mobilizações em busca da emancipação.

Quando essa retórica é apropriada pelas elites, o movimento emancipatório se desvia do real motivo de sua existência: a busca pela liberdade. Para o autor, isso se evidencia quando dirigentes de movimentos como Black Lives Matter se posicionam contra o ensino público, a favor da privatização de escolas, e defendem proposição de testes de drogas em estudantes, mesmo sabendo que os alunos negros seriam os mais atingidos pelas medidas, considerando que a aprovação das referidas medidas significaria uma evasão escolar massiva de estudantes negros e pobres.

O distanciamento das bandeiras de identidade da luta anticapitalista abre espaço para que as pautas sejam angariadas pelo neoliberalismo. Neste momento, o autor defende que pautar as lutas apenas na liberdade individual constrói uma

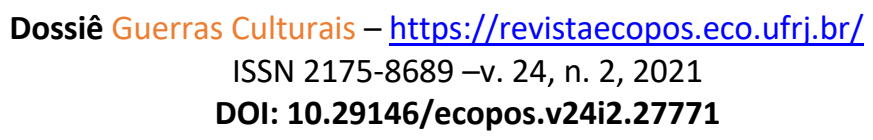


liberdade ilusória, porque perde de vista o que deve ser o propósito das mobilizações.

\section{3.}

Em um exercício histórico e etiológico no terceiro trecho do livro, o autor traça um panorama do que se entende por "ideologia racial", já situando "raça" esse complexo, escorregadio e, ao mesmo tempo, óbvio fenômeno diante dos olhos da sociedade - no lugar da significação arbitrária. Haider explica que a forma primordial de "raça" é a branca e, portanto, não deve ser a partir dela que se define o diferente: "Nos discursos da política identitária, a categoria de raça branca raramente é teorizada porque acaba sendo instrumentalizada para fundamentar o privilégio branco" (p.97), diz, fazendo conexão ao outro lado desta expressão, a culpa branca, que, para ele, reproduz a ficção fundante da raça. Assim, propõe explicar a branquidade a partir da estrutura social e suas relações constituintes.

Por outro lado, rejeita a posição a que chama de positivista de que a classe importa mais do que a raça. Para ele, é um dos principais obstáculos ao socialismo. Dissociando a ideia genérica de escravidão à ideologia racial - "A escravidão nem sempre é racial" (p.110), Haider situa a formação da supremacia branca e da invenção da raça branca como forma de controle social no bojo da transição para o capitalismo, por causa da centralidade para a escravidão racial. Por isso, lutar contra ela é lutar pela emancipação universal, o que foi ignorado pelos movimentos socialistas americanos do final do século XIX e início do XX, ainda que muitos dos primeiros partidos socialistas eram em maioria compostos por imigrantes ainda não muito incorporados à raça branca. "0 custo dessa indiferença com a raça foi que o socialismo acabou tendo sempre que concorrer com a branquidade para angariar membros"(p.125), observa o autor.

Dossiê Guerras Culturais - https://revistaecopos.eco.ufrj.br/

ISSN 2175-8689-v. 24, n. 2, 2021

DOI: 10.29146/ecopos.v24i2.27771 
Lançando mão das críticas contidas em "Against Race" (2000), de Paul Gilroy, Haider descreve a relação dos oprimidos com suas identidades como ambivalentes:

"Quando não há outro esforço organizativo para combater o racismo, qualquer questionamento da concepção de identidade pode parecer uma tentativa de negar a validade da luta antirracista. Na verdade, mais do que isso. Questionar a própria ideologia racial pode parecer uma negação da capacidade de agir dos oprimidos. " (Haider, 2019, p.123).

O historiador também argumenta que os interesses em comum são construídos em um processo de prática política, ou seja, são feitos no devir e não estão dados a priori.

4.

O quarto capítulo recebe o nome de passing, expressão sem tradução equivalente em português, que livremente poderia significar passagem. Mas talvez o termo mais próximo seja "passabilidade". Mesmo assim, tal tradução não daria conta, uma vez que, nos EUA, passing "se reporta a passagem racial em que o afroamericano se passa por branco ou passa a ser lido como Branco, isto é, se integra ou se insere na sociedade ou meio social dos brancos" (p. 95).

Haider começa o capítulo rememorando o caso da professora em estudos afroamericanos da universidade de Eastern Washington Rachel Dolezal, uma mulher branca que se passou por negra durante anos e chegou a ser presidente da National Association for the Advancement of Colored People (NAACP, ou Associação Nacional para o Avanço das Pessoas de Cor). 0 caso Dolezal ganhou amplitude nacional nos Estados Unidos e levantou muitos debates na comunidade negra estadunidense e mundial sobre a definição da identidade racial. Rachel foi convidada para entrevistas na TV e, durante uma dessas, ela irredutivelmente afirmou que se reconhece (se autoidentifica) como negra.

Dossiê Guerras Culturais - https://revistaecopos.eco.ufri.br/

ISSN 2175-8689-v. 24, n. 2, 2021

DOI: 10.29146/ecopos.v24i2.27771 
Considerando a afirmação de uma herança negra inexistente em Rachel, Haider salienta como a inflexível defesa de uma negritude dela demonstra a fragilidade da determinação de uma identidade racial a partir da autoafirmação, principalmente se esta estiver conectada à busca pela emancipação individual.

Para Haider, passing é uma condição universal (p. 112) que revela muito sobre o que ele caracteriza como *identitarismo*, uma vez que afeta os indivíduos e reduz as políticas de identidades apenas à performance.

\section{5.}

De título "Lei e ordem", Haider traz no quinto capítulo uma reflexão a partir das descrições de Stuart Hall sobre o encontro entre uma crise de classe e raça e o desaparecimento do consenso durante os anos de parlamento de maioria do Partido Trabalhista, a partir do final dos anos 1960. Em "Policing the crisis" (2013), Hall caracterizou as "crises hegemônicas" ao relacionar as representações raciais nas mudanças políticas e econômicas. Descreve Hall, "Policiar os negros se misturou ao problema de policiar os pobres e de policiar os desempregados: todos os três estavam concentrados exatamente nas mesmas áreas urbanas" (apud Haider, p.215). Alimentada pela mídia de massa e pela retórica de políticos, a prática de "policiar os negros" se tornou "sinônimo da questão maior de policiar a crise" (p. 166). Para Hall, era uma crise em via de mão dupla: tanto a organização dos trabalhadores foi debilitada pela ideologia da divisão racial, quanto pelo desemprego. A falta de acesso ao mercado de trabalho, por outro lado, estava bastante relacionada à raça pela experiência cotidiana.

Neste contexto, o intelectual britânico destaca como a criação de um "pânico moral de assaltos" foi usada para obter apoio às medidas repressivas do Estado promovidas após a eleição da direita radical com Margareth Thatcher, apoiadas na 
ideologia que dá nome ao capítulo². Na leitura de Haider, o livro de Hall mostra as brechas deixadas pelas contradições do Partido Trabalhista, que teriam desorganizado as respostas à crise da esquerda e da classe trabalhadora. 0 questionamento de Hall ao caráter masculinista dos movimentos, que os impediam de chegar a uma luta social mais ampla, foram criticados por intelectuais como Ralph Miliband. O sociólogo chamava de novos movimentos sociais aqueles que surgiram fora das organizações dos trabalhadores e que tinham demandas relativas à raça, a gênero, à sexualidade, à ecologia e outros temas que não eram apresentados explicitamente em termos de classe.

Em contraponto, Haider volta a lançar mão do pensamento de Gilroy orientando de Hall -, ao propor uma análise materialista e não platônica, "onde as 'raças' se localizam entre o mundo das relações reais e o mundo das formas" (p.180). Este tipo de análise empenha-se em "mostrar como significações raciais, solidariedade e identidades constituíam a base para ação"(p.180). Repetindo a resposta a Miliband por Marion Kozak, ativista e esposa dele, o sociólogo "exagerou a primazia da classe e não atribuiu peso suficiente aos movimentos sociais, enxergando-os como fragmentadores em vez de potenciais aliados de movimentos de classe" (p.180).

Em síntese, no contexto britânico, tanto o movimento de classe quanto os ditos novos movimentos saíram perdendo, na visão do autor. Ele afirma que as reivindicações do ativismo de raça, gênero, entre outros, foram preservadas, havendo avanço no nível cultural. Mas ficaram cada vez mais distantes de um movimento de massa, o que contribuiu para poupar as estruturas materiais. "Como resultado, as linguagens progressistas dos novos movimentos sociais, desenraizadas

\footnotetext{
2 Em Necropolítica (2019), Achille Mbembe disserta sobre como a elaboração de um "inimigo fictício" serve para criar um estado permanente de exceção.
}

Dossiê Guerras Culturais - https://revistaecopos.eco.ufrj.br/

ISSN 2175-8689 -v. 24, n. 2, 2021

DOI: 10.29146/ecopos.v24i2.27771 
da sua base popular, seriam apropriadas como nova estratégia da classe dominante" (p.182), completa o autor.

O paralelo com o contexto britânico pode oferecer recursos para o pesquisador que busca trazer as reflexões e avaliar a pertinência da obra para o caso da América Latina, especialmente do Brasil.

6.

No último capítulo do livro, Haider se ancora em obras dos pensadores Paul Gilroy e Stuart Hall para traçar um paralelo entre as experiências de organização de mobilizações populares no Reino Unido e nos Estados Unidos. Haider evoca Hall, que estabelece o capital como um dos causadores da diferença de raça e das desigualdades geradas por este cenário. Na experiência do Reino Unido, a organização racial se deu a partir de um viés de classe e a luta antirracista se imbricou à luta de classes construindo uma análise de lutas mútuas e organizadas com uma mesma finalidade "a superação da exploração" (p.125).

Paul Gilroy justifica que o racismo é um fenômeno que precisa ser captado como político, ideológico e econômico, e que exige mudanças também a partir desses três pontos. Gilroy é chamado para pensar a diáspora como uma ruptura da ideia de um nacionalismo imóvel, uma vez que ela é um dos maiores símbolos de trânsito das identidades, como afirma Haider ao revistar Atlântico Negro (2001), de Gilroy.

De saída, o autor propõe o que ele chama de "universalidade insurgente", convergência composta por mulheres, pobres e negros rumo à emancipação coletiva, distante da ideia de um sujeito entendido como único e capaz de superar a individualização das políticas de identidade para transformá-las em construções coletivas. O autor discorre, ao final, sobre um "universalismo estratégico" apresentado como uma perspectiva de acolher as diversas identidades em torno de uma luta de classes.

Dossiê Guerras Culturais - https://revistaecopos.eco.ufri.br/

ISSN 2175-8689-v. 24, n. 2, 2021

DOI: 10.29146/ecopos.v24i2.27771 


\section{Considerações}

A obra ocupa um lugar importante para as reflexões contemporâneas sobre raça e classe construindo tensionamentos com o neoliberalismo. A fundo, o texto traz a necessidade de perspectivas políticas não individualizadas para questões que são coletivas. Mas deixa de considerar limites da teoria marxista para analisar as complexidades da escravidão racial - que mais do que trabalhadores sem liberdade e não remunerados, eram pessoas sequestradas de seus territórios, do próprio status de humanidade e relegadas à condição de mercadoria. Ao buscar a formação de uma subjetividade radical negra em Anseios (2019), bell hooks faz o que pode ser um "contraponto dialógico" à proposta de Haider, rejeitando "um descarte arrogante das políticas identitárias" e descrevendo a relação dos oprimidos com suas identidades como ambivalentes:

"Qualquer crítica que explore o potencial radical do pós-modernismo em sua relação com a diferença e com a dominação racial, deveria levar em consideração as implicações para os grupos oprimidos de uma crítica ao conceito de identidade. Muitos de nós estamos lutando para encontrar novas estratégias de resistência. Devemos nos engajar na descolonização como uma prática crítica se quisermos ter chances reais de sobrevivência, mesmo que, para isso, tenhamos que lidar com a perda das bases políticas que possibilitaram o radicalismo político." (hooks, 2019, p.76/77).

Aqui, cabe destacar, hooks não faz a defesa de uma "identidade autêntica". Ao contrário, também se coloca crítica ao essencialismo e defende o direito dos oprimidos de se tornarem sujeitos, provocando uma mudança "a partir das margens".

Convém mencionar para o desenvolvimento da questão proposta no livro a aplicação das ações afirmativas no Brasil, atualmente instituídas por lei federal (nº

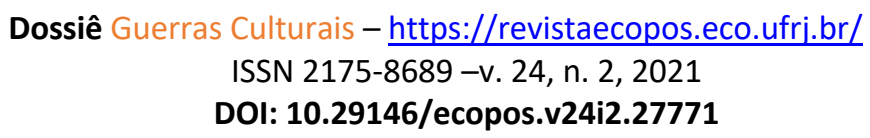


12.711/2012), que estabelece cotas econômicas e raciais para o ensino superior público. Duas décadas depois das primeiras experiências, a política pública tem se apresentado como um importante ${ }^{3}$ instrumento de transformação social, não apenas do ponto de vista da inclusão educacional e da mobilidade social, mas também para reconstituir comunidades e agentes de mudanças também estruturais, em oposição ao mito da democracia racial ${ }^{4}$. 0 caso pode salientar os diferentes contornos da discussão racial no contexto brasileiro, onde raça e classe talvez estejam mais profundamente inseparáveis. Intelectuais como Guerreiro Ramos e Clóvis Moura também buscaram fazer o debate racial dentro do marxismo. Na obra "Sociologia do Negro brasileiro" (1988), Clóvis Moura já apresentava a formação da sociedade brasileira e das relações raciais existentes a partir de uma análise dialética.

Conforme apontou Silvio Almeida em seu prefácio, mesmo que a análise de Haider esteja localizada nos Estados Unidos, é possível extrair provocações pertinentes para pensar a prática política na América Latina. No entanto, a formação social deste território traz peculiaridades importantes ao debate geral sobre a relação entre as categorias de raça e classe. Como Almeida mencionou,

"é impossível contar a história da formação social dos países da América Latina, da África, da Ásia e da Oceania sem levar em conta o modo como as lutas políticas foram organizadas a partir de uma concepção revolucionária da identidade e como as lutas anticoloniais tiveram na afirmação de uma "identidade nacional" negra e/ou indígena o seu ponto de ebulição (Almeida, apud Haider, 2019, p.19)

\footnotetext{
${ }^{3}$ Garcia. Janaina, A esperança vem em cotas. Ecoa - UOL. São Paulo. 2 de dezembro de 2020. Acesso em: https://www.uol.com.br/ecoa/reportagens-especiais/educacao-primeiros-cotistas/\#cover 4 A ideia- há muito já contraposta pela sorte de intelectuais brasileiros, especialmente negros - , fundamentada durante a década de 1930, especialmente com a publicação de Casa Grande e Senzala (1933), de Gilberto Freyre, que defendia que a escravidão não foi tão dura e cruel, de que houve harmonia entre os senhores e escravos, trazendo a noção da possibilidade de uma igualdade racial, tendo também em vista o processo de culturalização e miscigenação no Brasil.
}

Dossiê Guerras Culturais - https://revistaecopos.eco.ufrj.br/

ISSN 2175-8689-v. 24, n. 2, 2021

DOI: 10.29146/ecopos.v24i2.27771 
O contexto brasileiro, a história dos movimentos por direitos da população negra e a fortuna crítica de intelectuais brasileiros negros podem oferecer respostas ou, ao menos, reconsiderações aos dilemas apresentados na obra. A ideia de identificação, apresentada por Muniz Sodré, em seu Claros e Escuros (1999) também reconhece a ideia de identidade como "armadilha" política e "estável e garantida por si mesma", mas parece oferecer uma perspectiva que reconheça as diferenças sem a perda da solidariedade, Movediça, grupal, afetiva, mediática - como o próprio autor descreve -, essa categoria permite colocar em crise figuras das doutrinas tradicionais, de classe, função e gênero.

\section{Referências bibliográficas}

HAIDER, Asad. Armadilha da identidade: raça e classe nos dias de hoje. Trad.:Leo Vinicius Liberato. São Paulo: Veneta, 2019.

hooks, bell. Anseios: raça, gênero e políticas culturais. Trad. Jamille Pinheiro Dias. São Paulo: Elefante, 2019.

MOURA, Clóvis. Sociologia do negro brasileiro. Editora Perspectiva SA, 2020.

SODRÉ, Muniz. Claros e escuros: identidade, povo, mídias e cotas no Brasil. São Paulo: Vozes, 1999.

SODRÉ, Muniz. Pensar Nagô. São Paulo: Vozes, 2017. 